\title{
Synthesis and Electrochemical Performance of Tungsten Carbide
}

\author{
I. JOSHI, K. KHATI, A. BISHT, R. REKHARI, S. MEHTAB and M. G. H. ZAIDI \\ Department of Chemistry, G.B. Pant University of Agriculture and Technology, Pantnagar, \\ Uttarakhand-263145, India \\ ilajoshi15@gmail.com
}

Received 27 May 2018 / Accepted 5 July 2018

\begin{abstract}
Tungsten carbide (WC) was synthesized via modified polymer precursor method. The formation of WC was ascertained through Fourier-transform infrared spectra (FT-IR), x-ray diffraction (XRD), thermogravimetry analysis (TGA) and differential thermo analysis (DTA). The WC electrode was synthesized over 316 stainless steel to evaluate electrochemical performance through cyclic voltammetry (CV). The CV curves of WC electrode were found in the potential span of -0.6 to $0.0 \mathrm{~V}$ in $\mathrm{KOH}(1.0 \mathrm{M})$. The WC electrode shows specific capacitance $(\mathrm{Cs})$ of $110 \mathrm{~F} / \mathrm{g}$ at $0.001 \mathrm{~V} / \mathrm{s}$ and good cyclic stability over 500 cycles.
\end{abstract}

Keywords: Tungsten carbide, Cyclic voltammetry, Electrochemical capacitance

\section{Introduction}

Supercapacitors (SCs) also known as electrochemical capacitors are energy storage devices having similarities with batteries and conventional capacitors but unlike batteries they store only electric energy ${ }^{1}$. SCs serve for bridging the energy gap between traditional capacitors with high power output and batteries with high energy storage capacity ${ }^{2-4}$. The charge storage capacity of SCs mainly depends on the type of electrode materials. The materials having high surface area, good electrical conductivity and thin electrolytic dielectrics are more reliable for energy storage devices ${ }^{1}$. Therefore, the new category of material i.e., metal carbides and nitrides recently have been introduced due to its exceptional chemical and physical characteristics ${ }^{5}$.

The atoms like carbon, nitrogen and oxygen are easily dissolve in the interstitial sites of early transition metal lattice. Therefore, the resultant alloys are identified as metal carbides, nitrides and oxycarbides ${ }^{6}$. Due to their high strength and durability, they are used for making rocket nozzles and drill bits under utmost temperature and pressure ${ }^{7}$. Transition metal carbides are also widely used in the field of technology due to their high catalytic, magnetic and electronic properties ${ }^{8-12}$.

In this paper, we investigate the electrochemical behavior of tungsten carbide (WC) electrodes for energy storage. We have also studied the charge-discharge characteristics of WC electrode. 


\section{Experimental}

Ammonium metatungstate (AMT), resorcinol and formaldehyde were purchased from Sigma-Aldrich. Chlorosulfonic acid (98\%) was procured from Across Chemicals, PSO ( $\mathbf{M}_{n}$, 26,000) from Aldrich Chemicals and graphite $(500 \mu \mathrm{m})$ from Loba. Other chemicals and solvents were used without further purification.

\section{Synthesis of WC and SPS}

WC was synthesized using a modified polymer precursor route procedure ${ }^{12}$. Typically, $5.00 \mathrm{~g}$ of AMT and $1.25 \mathrm{~g}$ of resorcinol were dissolved in $1.65 \mathrm{~mL}$ of formaldehyde and $20 \mathrm{~mL}$ of de-ionized water. The resultant solution then refluxed at $90{ }^{\circ} \mathrm{C}$ for one day. Then precipitate of $\mathrm{WC}$ was washed with de-ionized water and dried at $50 \pm 1{ }^{\circ} \mathrm{C} / 400 \mathrm{~mm} \mathrm{Hg}$ over 24 hours.

PSO resin (7.2 g) was dissolved in dichloromethane (DCM) $(75 \mathrm{~mL})$ in a two neck flask at $20 \pm 1{ }^{\circ} \mathrm{C}$ under stirring at room temperature. To this the solution of chlorosulphonic acid in DCM was added drop wise with stirring over $2 \mathrm{~h}$. The precipitated SPS was filtered and washed with $\mathrm{NaOH}(10 \%)$. Finally, SPS was washed with de-ionized water and dried at $50 \pm 1{ }^{\circ} \mathrm{C}$ overnight ${ }^{13}$.

\section{Preparation of the working electrodes}

The metallic substrates for electrode $\left(2 \mathrm{~cm}^{2}\right)$ area were fabricated through cutting a commercially available 316-SS sheet. Prior to deposition of electroactive material, surface of electrode was well polished with emery paper (mesh size 320600), followed by cleaning the surface with acetone. Working electrodes were prepared through depositing $(100 \mu \mathrm{L})$ an ultrasonically prepared suspension comprising electroactive material $(65 \mathrm{mg})$, graphite $(10 \mathrm{mg})$ and SPS in NMP $(5 \mathrm{~g} / \mathrm{dL})$ over SS substrate. The treated electrodes were dried at room temperature for $8 \mathrm{~h}$, followed by $60{ }^{\circ} \mathrm{C} / 400 \mathrm{~mm} \mathrm{Hg}$ for $48 \mathrm{~h}$. This has afforded electrodes with a mass thickness of electroactive materials by $0.04 \pm 0.01 \mathrm{mg}^{13-14}$.

\section{Characterization}

FT-IR spectra of samples were recorded on thermo Nicolet in $\mathrm{KBr}$ from 4000 to $500 \mathrm{~cm}^{-1}$ on transmission mode. Thermo-oxidative stability was investigated through TG and DTA over EXSTAR TG/DTA 6300 instrument in static air at a heating rate of $10{ }^{\circ} \mathrm{C} /$ minutes a flow rate of $200 \mathrm{~mL} / \mathrm{min}$ in the temperature up to $700{ }^{\circ} \mathrm{C}$. XRD spectra of powdered samples were recorded at room temperature over Rigaku-Geigerflex, x-ray diffractometer using $\mathrm{Cu}$ $\mathrm{K} \alpha$ radiation $(\lambda=0.154 \mathrm{~nm})$ in the range of $5^{\circ}-90^{\circ}$.

All the electrochemical characterizations were made over IVIUM PotentiostatGalvanostat using a three electrode cell assembly. $\mathrm{Ag} / \mathrm{AgCl}$ was used as reference electrode. $\mathrm{Pt}$ electrode was used as counter electrode. $\mathrm{CV}$ was conducted at current compliance $1 \mathrm{~mA}$ in the range of $-0.6-0.0 \mathrm{~V}$, at $0.001-0.2 \mathrm{~V} / \mathrm{s}$ at ambient temperature.

\section{Results and Discussion}

\section{Spectra}

FT-IR spectra

Figure 1, depicts the FT-IR spectra of WC. WC shows symmetric stretches near the low frequency fingerprint region at ${ }^{15} 665.82 \mathrm{~cm}^{-1}$. The peak at $3583.31 \mathrm{~cm}^{-1}$ corresponds to symmetrical stretch of W..... OH, probably due to moisture ${ }^{16,17}$. 


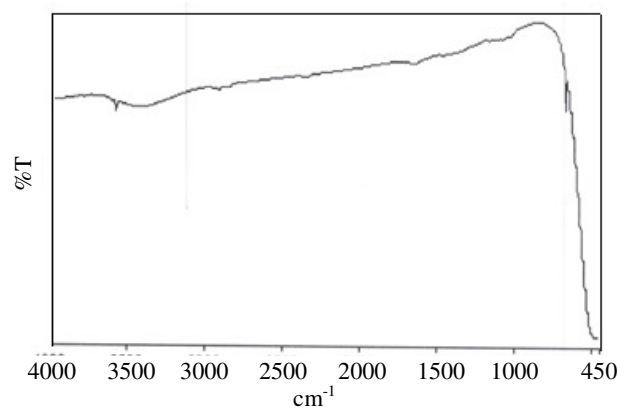

XRD spectra

Figure 1. FT-IR spectra of WC

The XRD spectra of WC are shown in Figure 2. For WC, the diffraction peaks at $31.49^{\circ}$ $(2.83), 35.70^{\circ}(2.51), 48.35^{\circ}(1.88), 64.16^{\circ}(1.45), 65.70^{\circ}(1.41), 73.22^{\circ}(1.29), 75.67^{\circ}(1.25)$, $77.12^{\circ}(1.23)$ and $84.20^{\circ}(1.14)$ are correspond to [001],[100], [101], [110], [002], [111], [200], [102] and [201] planes of hexagonal WC and well matched with JCPDS 73-0471 ${ }^{18}$.

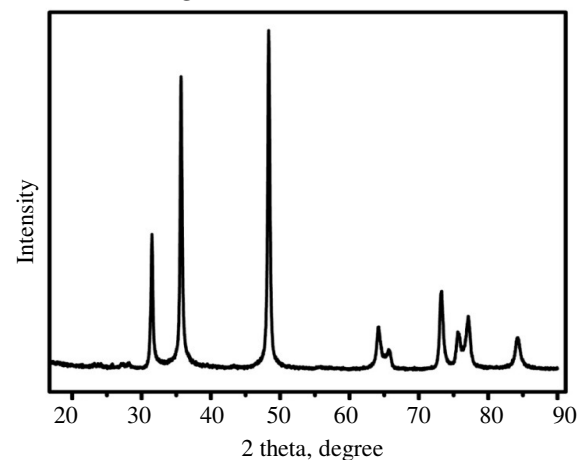

Thermal stability

Figure 2. XRD spectra of WC

Figure 3, display the TG and DTA of WC. WC was thermally stable up to $384^{\circ} \mathrm{C}$. WC was decomposed with $\mathrm{TG}$ onset at $528^{\circ} \mathrm{C}$. This was accompanied with weight gain of $4.90 \%$ due to oxidation ${ }^{18}$. Decomposition of WC was supported with a DTA signal $(0.22 \mathrm{mV})$ at $548{ }^{\circ} \mathrm{C}$. Maximum decomposition of WC was @ $-21.97 \mathrm{X} 10^{3} \mathrm{mg} /{ }^{\circ} \mathrm{C}$ at $552{ }^{\circ} \mathrm{C}$. The TG endset of WC was appeared at $597^{\circ} \mathrm{C}$ leaving char residue of 114.70 wt \%.

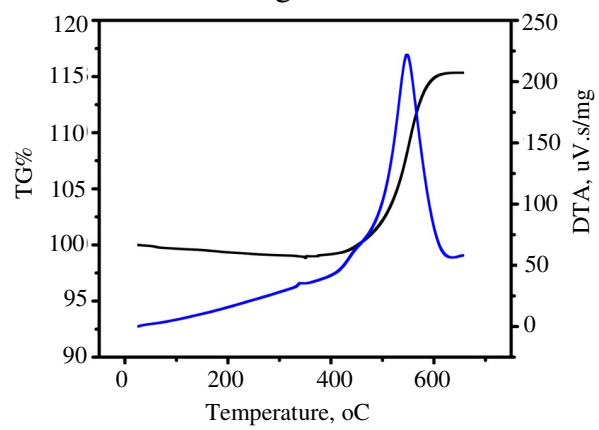

Figure 3. TG-DTA of WC 


\section{Electrochemical behavior}

The electrochemical behavior of WC were examined through $\mathrm{CV}$ using $\mathrm{KOH}(1.0 \mathrm{M})$ as an electrolyte at the common scan rate of 0.001 to $0.2 \mathrm{~V} / \mathrm{s}$ (Figure 4). A regular increase in the peak currents has been observed on increasing scan rate in the potential range of -0.6 to 0.0 $\mathrm{V}$ vs. $\mathrm{Ag} / \mathrm{AgCl}$. Calculations based on cathodic and anodic current reveals that WC display Cs (F/g) of $110.00 @ 0.001 \mathrm{~V} / \mathrm{s}$ (Figure 4a, 4b). Further to investigate, the cyclic performance of $\mathrm{WC}$, the scans was run upto 500 cycles at a scan rate of $0.1 \mathrm{~V} / \mathrm{s}$. The electrode shows good cyclic stability with negligible loss of Cs (Figure 4c). The chargingdischarging curve of WC electrode was recorded in the voltage range from - 0.6 to $0.0 \mathrm{~V}$ at an applied current density of $10 \mathrm{~mA} / \mathrm{cm}^{2}$. The charge-discharge curves are linear in the full potential span, depict good capacitive behavior (Figure 4d).
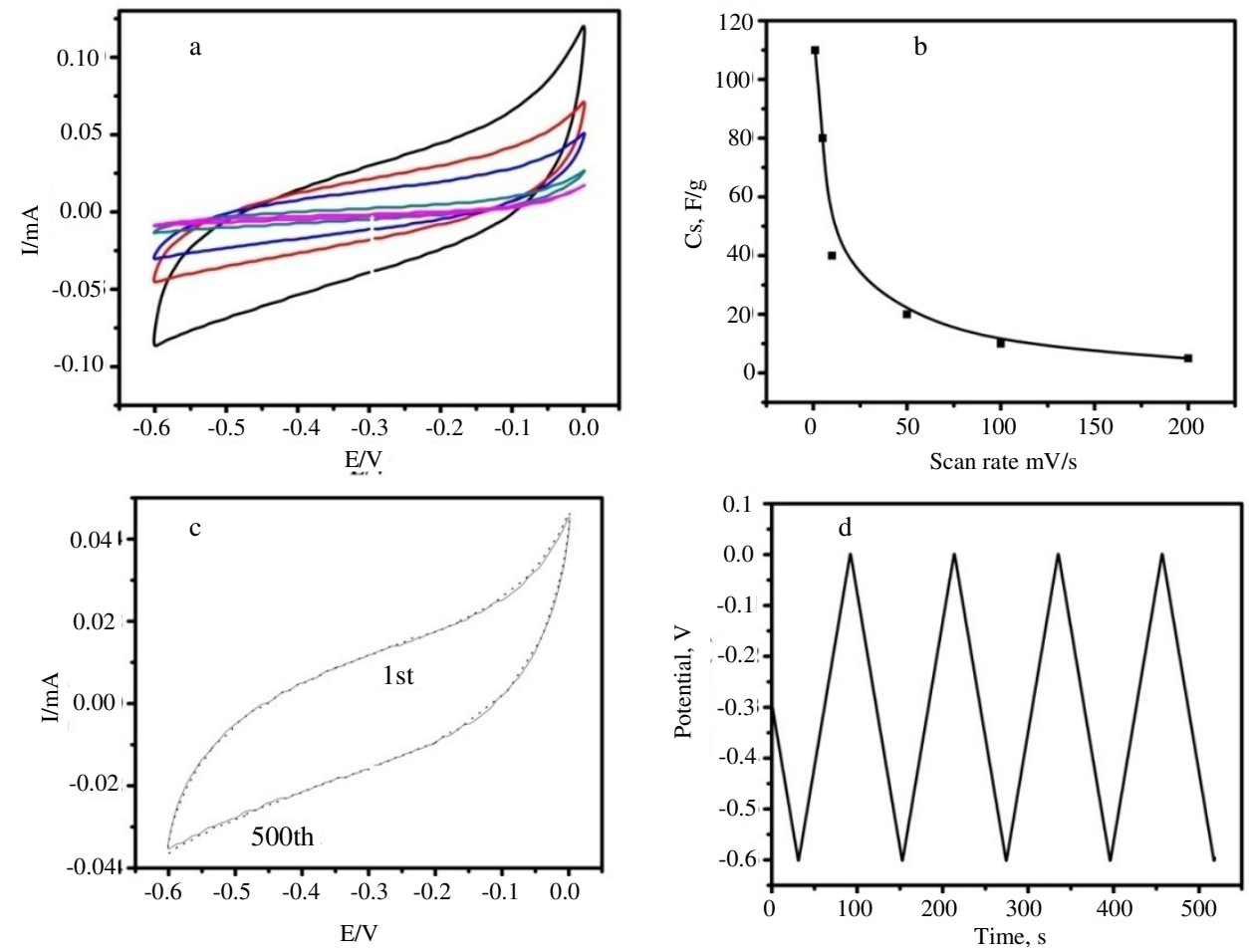

Figure 4(a). Cyclic voltammetry (CV) of $\mathrm{WC}$ vs $\mathrm{Ag} / \mathrm{Ag}^{+}$electrode at 0.001-0.2 V/s scan rate. (b) Effect of scan rate on $\mathrm{Cs}$ of WC. (c) $\mathrm{CV}$ of WC at $0.1 \mathrm{~V} / \mathrm{s}$ up to 500 cycles. (d) Charge-discharge curve of WC

\section{Conclusion}

The modified polymer route method was used to synthesize WC. The formation of WC was confirmed by diversified analytical techniques. The sulphonated polysulphone binder based WC electrode was fabricated to study the electrochemical characteristics. The electrochemical performance of WC has been examined through $\mathrm{CV}$ and the Cs calculated from I/V curve is $110 \mathrm{~F} / \mathrm{g} @ 0.001 \mathrm{~V} / \mathrm{s}$. The charge-discharge curve depicts good electrochemical behavior. 


\section{Acknowledgement}

The authors also thanks G.B. Pant University of Agricultural and Technology, Pantnagar, India, is thankfully acknowledge for providing the laboratory facilities.

\section{References}

1. Chen T and Dai L, Materials Today, 2013, 16(7-8), 272-280;

DOI:10.1016/j.mattod.2013.07.002

2. Kötz R and Carlen M, Electrochimica Acta, 2000, 45(15-16), 2483-2498; DOI:10.1016/S0013-4686(00)00354-6

3. Simon P and Gogotsi Y, Nature Materials, 2008, 7(11), 845-854.

4. Manthiram A, Murugan A V, Sarkar, A, and Muraliganth T, Energy Environmental Science, 2008, 1(6), 621-638; DOI:10.1039/B811802G

5. Pande P, Rasmussen P G and Thompson L T, Journal Power Sources, 2012, 207, 212-215; DOI:10.1016/j.jpowsour.2012.01.028

6. Oyama S T, Catalysis Today, 1992, 15(2), 179-200; DOI:10.1016/09205861(92)80175-M

7. Oyama S T, Springer, Dordrecht, 1996.

8. Claridge J B, York A P, Brungs A J and Green M L, Chem Maters., 2000, 12(1), 132142; DOI: $10.1021 / \mathrm{cm} 9911060$

9. Li P, Liu Z, Cui L, Zhai F, Wan Q, Li Z, Fang Z Z, Volinsky A A and Qu X, Int J Hydrogen Energy, 2014, 39(21), 10911-10920; DOI:10.1016/j.ijhydene.2014.04.173

10. Palanker V S, Sokolsky D V, Mazulevsky E A and Baybatyrov E N, Electrochimica Acta, 1977, 22(6), 661-667; DOI:10.1016/0013-4686(77)85136-0

11. Jeong I, Lee J, Joseph K V, Lee H I, Kim J K, Yoon S and Lee J, Nano Energy, 2014, 9, 392-400; DOI:10.1016/j.nanoen.2014.08.010

12. Zhu W, Ignaszak A, Song C, Baker R, Hui R, Zhang J, Nan F, Botton G, Ye S and Campbell S, Electrochimica Acta, 2012, 61, 198-206; DOI:10.1016/j.electacta.2011.12.005

13. Mudila H, Zaidi M G H, Rana S, Joshi V and Alam S, Int J Chem Analytical Science, 2013, 4(3), 139-145; DOI:10.1016/j.ijcas.2013.09.001

14. Goel S, Mazumdar N A and Gupta A, J Nanosci Nanotechnol., 2011, 11(11), 1016410172; DOI:10.1166/jnn.2011.4993

15. Cheong Y K, Calvo-Castro J, Ciric L, Edirisinghe M, Cloutman-Green E, Illangakoon U E and Ren G, Nanomaterials, 2017, 7(7), 152;

DOI:10.3390/nano7070152

16. Delichere P, Falaras P, Froment M, Hugot-Le Goff A and Agius B, Thin Solid Films, 1988, 161, 35-46; DOI:10.1016/0040-6090(88)90233-7

17. Pfeifer J, Guifang C, Tekula-Buxbaum P, Kiss B A, Farkas-Jahnke M and Vadasdi K, J Solid State Chem., 1995, 119(1), 90-97; DOI:10.1016/0022-4596(95)80013-F

18. Liu C, Zhou D, Zhou J, Xie Z and Xia Y, RSC Advances, 2016, 6(80), 76307-76311; DOI:10.1039/C6RA12545J 